\title{
Integrated Assessment of Quality of Service of Wireless Networks Deployed In Tomsk
}

\author{
Dmitriy B. Shmakov \\ Department of Television and Control \\ Tomsk State University of Control Systems and Radioelectronics \\ Tomsk, Russia \\ dshrfe@gmail.com
}

\begin{abstract}
This paper presents the integrated assessment of quality of service of GSM 900/1800, UMTS and LTE mobile networks deployed in Tomsk and the analysis of their coverage quality. It also presents the results of the measurements of key quality indicators for the mobile telecommunications operators and conclusions about the actual quality of the cellular services in Tomsk. In this study we used drive-tests to perform the measurements and obtain the results. The measuring equipment used in this study is described in detail. Some aspects of the measurement procedure are outlined. The results of this study can be used both by Tomsk residents to make an informed choice of mobile operator and by mobile operators to revise their network development plans. The techniques described in the paper can be useful for conducting similar research in other cities and countries.
\end{abstract}

Keywords - drive-tests; mobile network; quality of service; coverage quality; measuring equipment

\section{INTRODUCTION}

Cellular communication in the modern world is extremely important. Without any exaggeration it can be said that almost every citizen of the Russian Federation is a mobile phone user. According to the data provided by The Ministry of Communications and Mass Media of the Russian Federation at the end of 2015, the telephone density in Russia was 193.8 mobile phones per 100 people [1].

One of the most challenging issues for the development of the telecommunications industry is to ensure that consumers are satisfied with the quality of communication services and are able to make an informed choice of service provider. In the furtherance of this goal, quality of service management issues should be solved [2]. Drive tests are widely used throughout the wireless industry for coverage assessment and performance monitoring in Russia and abroad: in Belarus [3], in Great Britain [4], in Germany [5] and in other countries. Such studies are conducted by both equipment manufacturers and mobile operators, as well as by local communication administrations.

In order to obtain an objective assessment of the quality of mobile communication services in Tomsk, specialists of the Federal State Unitary Enterprise "Radio Frequency Center of the Central Federal Area" made measurements in accordance with the methodology [6] from December 8, 2015 to January 25,2016 . The results of the measurements are summarized and available freely on the Internet [7]. It should be noted that such a large-scale study of Quality of Service (QoS) in cellular networks was conducted on the territory of Tomsk for the first time, and heretofore no analysis of the data obtained during the study has been performed.

Nevertheless, it seems appropriate to perform the analysis of the data to assess the actual quality of communication services. Such assessment can be useful for providing Tomsk residents with the information that will allow them to make an informed choice of mobile operator. Also, the assessment can be useful for mobile operators themselves, allowing them to revise their network development plans. The description of the measurement procedure can be useful for carrying out similar studies in the future. Papers containing an analysis of the results obtained have already been published by the author of this paper $[8,9]$. However the description of the measurement equipment used in this study, the principles of its operation and the measuring methods remain undisclosed.

The purpose of this paper is to fill this gap and present in a single paper the comprehensive assessment of the quality of cellular communication services in Tomsk.

\section{Measurement Procedure}

Measurements with the use of mobile measuring systems (drive tests) were conducted within the administrative boundary of the city of Tomsk on working days from 8 till 22 (local time). The main traffic arteries of the city, as well as internal development roads and courtyards were covered by the measurements. The total mileage of the measuring vehicle during the study was more than $4700 \mathrm{~km}$.

According to [2], drive tests are the most objective method of assessment inasmuch as they are performed in accordance with the approved measuring techniques with the use of technical test facilities - testing complexes. The testing complexes as such are specialized customer equipment that has the most complete functionality and supports all the wireless technologies available in a certain telecommunication network, the modes of its operation, all the frequency bands used in this network.

Drive tests are carried out by qualified personnel; the measuring procedure requires a large number of test samples in order to ensure the required reliability of the results. These facts allow obtaining the assessment that most fully reflects the potential quality of services provided by the operator. Drive testing is a very costly and time consuming way of assessing 
quality of service, which limits the possibility of using drivetests on a regular basis.

We will describe configuration of measuring equipment. Radio monitoring equipment used in this study for testing and monitoring network performance from the subscriber point of view (hereinafter - TEMS) is a radio measuring complex with a centralized data storage and processing system. TEMS is intended to carry out evaluation tests, collect and store the results, process the data obtained and calculate the key performance indicators in the mobile GSM, UMTS and LTE networks.

TEMS consists of the following components:

- Mobile radio monitoring equipment - mobile remote test units (remote test units, hereinafter - RTU) installed in the testing vehicle are used for continuous monitoring of the quality of services provided.

- Pocket radio monitoring equipment - portable remote test units (test pocket remote, hereinafter - TPR) are used for monitoring of the quality of wireless voice and data services inside buildings and in pedestrian areas.

- Local module for adjustment and control of RTUs.

- Local module for adjustment and control of TPRs.

- Server equipment.

Let us consider in more detail the configuration of the aforementioned components of TEMS. The radio monitoring equipment of TEMS includes 5 RTU testing modules.

Configuration of RTU:

- Voice modem Ericsson F3607 EU (2 pcs.).

- Modem for data transmission Sierra Wireless MC7710 (1 pc.).

- GPS antenna (1 pc.).

- LAN router, 5 ports (1 pc.).

- Scanning receiver PCTel SeeGull (1 pc.).

- Universal radio network analyzer R\&S TSMW (1 pc.).

- Power adapter $110 \backslash 220 \mathrm{~V}$ (4 pcs.).

- Uninterruptible power supply unit (1 pc.).

- External GPS antenna (5 pcs.).

- External antenna PCTel Z3438 (6 pcs.).

- Power divider MTS Power Divider LT4-544P-A21\4 (4 pcs.).

- 11200 mAh battery pack.

- Special software.

The portable radio monitoring equipment of TEMS includes Sony Xperia V LT25i TPR modules for monitoring of the quality of wireless voice and data services inside buildings and in pedestrian areas and the control tablet TEMS Pocket Premium Samsung Note 10 LTE for local configuration and control of TPR modules.

It should be noted that all the test modules used in this study support GSM, GPRS, EDGE, UMTS, HSPA, HSPA +, LTE technologies.

The server equipment of TEMS includes a server with benchmarking and testing software installed for monitoring the parameters of mobile communication services, data storing and post-processing and a server for testing the parameters of voice and data transmission services.
Currently the territory of Tomsk is covered by the networks of four mobile operators: public joint-stock company (PJSC) VimpelCom (hereinafter - Beeline), PJSC MegaFon (hereinafter - Megafon), Mobile TeleSystems PJSC (hereinafter - MTS), T2 Mobile LLC (hereinafter - Tele2). During the study we evaluated both the quality of the coverage (the level of the signal received by the user device from the base station) and a number of specific quality indicators determined in [6].

\section{MeAsurement Results}

The assessment of the coverage quality of GSM 900/1800 networks is given separately in Table 1 for each mobile operator (MTS, MegaFon, Beeline, and Tele2). To assess the coverage quality of the analyzed GSM 900/1800 networks we measured the RSSI-parameter (Received Signal Strength Indicator). It is generally believed that RSSI is a bad estimator of the link quality. However, according to [10], RSSI as a promising indicator when its value is above the sensitivity threshold.

The assessment of the coverage quality of UMTS networks is given separately in Table 2 for each mobile operator (MTS, MegaFon, Beeline, and Tele2). To assess the coverage quality of the analyzed UMTS networks we measured the RSCPparameter (Received Signal Code Power).

The assessment of the coverage quality of LTE networks is given separately in Table 3 for two mobile operators (MTS and MegaFon). The coverage quality of LTE networks of such mobile operators as Tele 2 and Beeline was not analyzed. These mobile operators lacked the required licenses at the time when the measurements were being conducted. It should be noted that the instrumental assessment of the quality of the MegaFon LTE network coverage was made together with the Yota LTE network. This approach to analyzing the MegaFon LTE network seems to be reasonable, considering the fact that Yota is a mobile virtual network operator (MVNO). To assess the coverage quality of the analyzed LTE networks we measured the RSRP-parameter (Reference Signal Received Power).

The names of the categories of coverage quality used in Tables 1-3 are conventional names; they are given for convenience of reference only and therefore quoted. The results presented in Tables 1-3 were processed and plotted on the map of Tomsk. These coverage maps for GSM 900/1800, UMTS and LTE networks are available on the official website [7]. Coverage maps for the LTE networks of Megafon and MTS are shown for example in Fig. 1.

The results of the measurements of specific quality indicators determined in [6] are given in Tables 4-6. The technique [6] gives detailed instructions for determining key quality indicators. However, it seems appropriate to describe some indicators given in Table 4 in detail. The values of the following parameters are given in Table 4:

1. Voice Service Non-Accessibility (VSNA)

$$
V S N A=\frac{Q}{N} \cdot 100 \%
$$


where $Q$ - the total number of unsuccessful attempts to establish a voice connection, $N$ - the total number of voice connections. An attempt to establish a voice connection is considered to be successful if the transmitting terminal detects a ring back tone and if the receiving terminal detects a call signal. An attempt to establish a voice connection is considered to be unsuccessful if the transmitting terminal detects a busy signal or if it fails to detect an answer signal due to network problems (even when the receiving terminal is registered on the network and not busy).

2. Voice service cut-off ratio (VSCR)

$$
V S C R=\frac{R}{N} \cdot 100 \%
$$

where $R$ - the number of link disconnections, $N$ - the total number of established voice connections (successful attempts).

3. Voice Speech Quality on Call basis (MOS POLQA) describes the quality of speech in the established voice connection for each test terminal in both directions. In this study to assess the quality of voice connections (speech intelligibility) we used the POLQA (Perceptual Objective Listening Quality Assessment) model defined by the ITU Recommendation P.863. This model is used to assess the quality of speech with the use of automated analysis methods (without participation of experts). The result is presented in the form of score according to the MOS (Mean Opinion Score) scale from 1 (bad) to 5 (excellent). This indicator was estimated without considering the possibility of voice transmission over LTE networks.

4. Negative MOS samples ratio (NMSR)

$$
\text { NMSR }=\frac{M}{N} \cdot 100 \%
$$

where $M$ - the number of received speech sequences with a speech intelligibility estimate less than 2.6 according to the POLQA model, $N$ - the total number of received speech sequences.

The parameters given in Table 6 were measured over the GSM, UMTS, LTE (if available) networks in aggregate for each operator. Table 7 provides reference data on the amount of measurements.

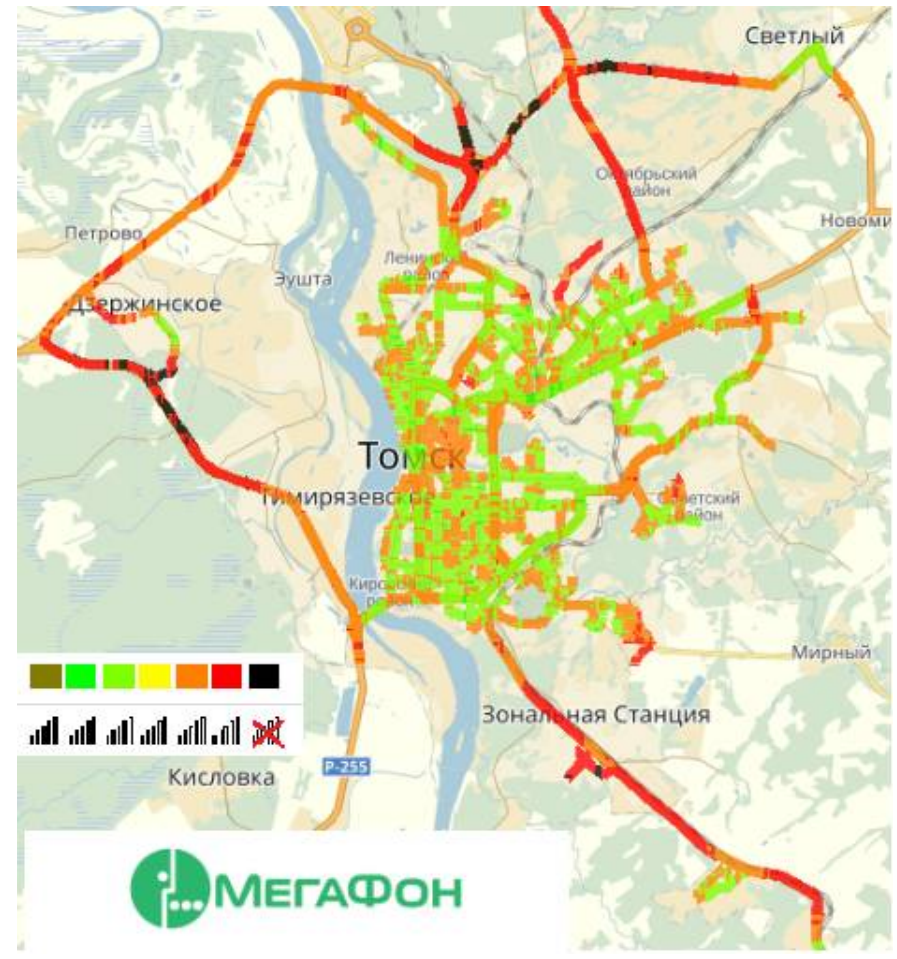

a)

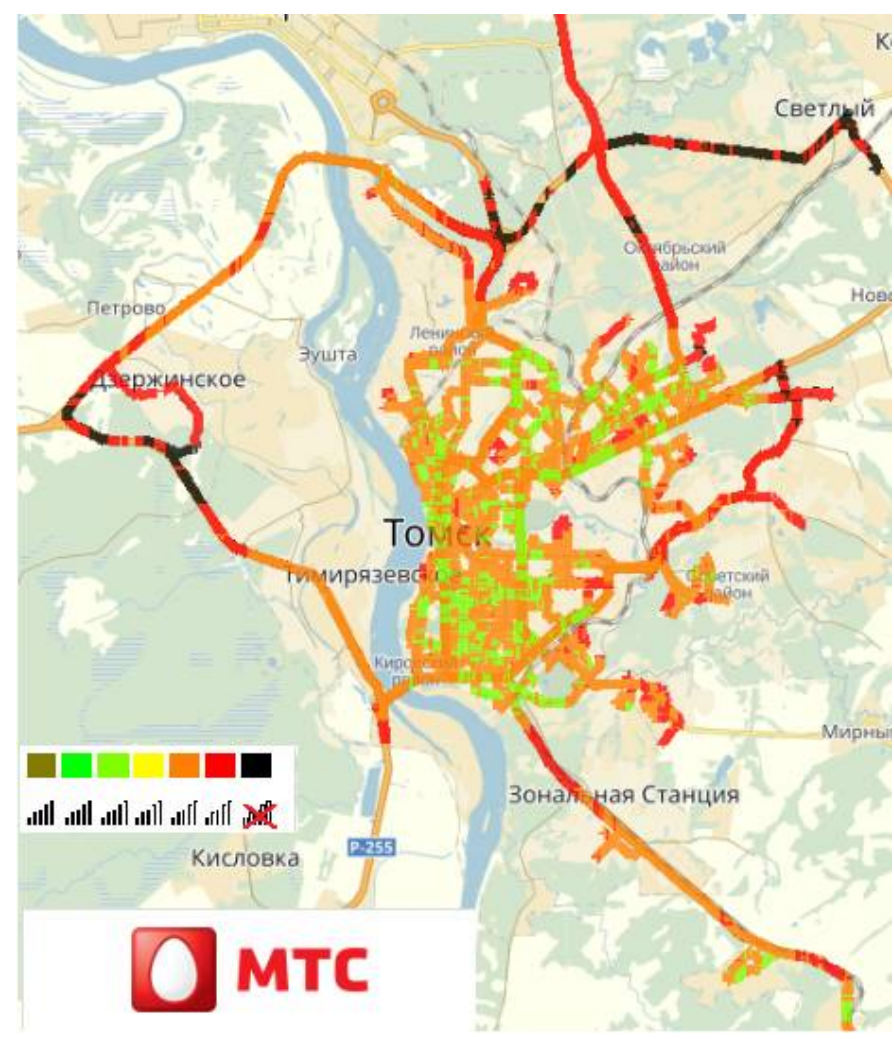

b)

Fig. 1. Coverage maps for the LTE networks of Megafon $(a)$ and MTS $(b)$ as of $29 / 01 / 2016$ 
TABLE I. THE ASSESSMENT OF THE COVERAGE QuALITY OF GSM 900/1800 NETWORKS

\begin{tabular}{|l|c|c|c|c|c|}
\hline Category of the & \multirow{2}{*}{$\begin{array}{c}\text { RSSI level, } \\
\text { dBm }\end{array}$} & \multicolumn{4}{|c|}{ Share (\% of the explored territory) } \\
\cline { 3 - 6 } & Beeline & Megafon & MTS & Tele 2 \\
\hline "Good" quality & -70 and more & 99.49 & 99.82 & 99.64 & 98.9 \\
\hline "Normal" & {$[-81 ;-70)$} & 0.50 & 0.18 & 0.35 & 1.04 \\
\hline "Sufficient" & {$[-85 ;-81)$} & 0.01 & 0 & 0 & 0.04 \\
\hline "Low" & {$[-95 ;-85)$} & 0 & 0 & 0.01 & 0.02 \\
\hline "Insufficient" & {$[-110 ;-95)$} & 0 & 0 & 0 & 0 \\
\hline "Absent" & less than -110 & 0 & 0 & 0 & 0 \\
\hline
\end{tabular}

TABLE II. THE ASSESSMENT OF THE COVERAGE QUALITY OF UMTS NETWORKS

\begin{tabular}{|l|c|c|c|c|c|}
\hline Category of the & \multirow{2}{*}{$\begin{array}{c}\text { RSCP level, } \\
\text { coverage quality }\end{array}$} & \multicolumn{3}{|c|}{ Share (\% of the explored territory) } \\
\cline { 3 - 6 } & dBm & Beeline & Megafon & MTS & Tele2 \\
\hline "Good" & -60 and more & 44.6 & 42.09 & 36.06 & 51.48 \\
\hline "Normal" & {$[-70 ;-60)$} & 31.43 & 30.63 & 37.68 & 26.03 \\
\hline "Sufficient" & {$[-80 ;-70)$} & 17.14 & 20.99 & 20.68 & 17.55 \\
\hline "Low" & {$[-90 ;-80)$} & 4.62 & 5.35 & 4.24 & 4.08 \\
\hline "Insufficient" & {$[-105 ;-90)$} & 2.04 & 0.89 & 1.23 & 0.8 \\
\hline "Absent" & less than -105 & 0.18 & 0.06 & 0.11 & 0.06 \\
\hline
\end{tabular}

TABLE III. The Assessment of The Coverage Quality of LTE NETWORKS

\begin{tabular}{|l|c|c|c|c|c|}
\hline Category of the & RSRP level, & \multicolumn{4}{|c|}{ Share (\%of the explored territory) } \\
\cline { 3 - 6 } coverage quality & dBm & Beeline & Megafon & MTS & Tele 2 \\
\hline "Normal" & {$[-60 ;-40)$} & - & 1.54 & 0.01 & - \\
\hline "Sufficient" & {$[-80 ;-60)$} & - & 46.24 & 16.7 & - \\
\hline "Low" & {$[-100 ;-80)$} & - & 42.37 & 68.8 & - \\
\hline "Insufficient" & {$[-120 ;-100)$} & - & 9.5 & 12.5 & - \\
\hline "Absent" & less than -120 & - & 0.35 & 1.99 & - \\
\hline
\end{tabular}

TABLE IV. THE INDICATORS OF VOICE CONNECTION QUALITY

\begin{tabular}{|l|c|c|c|c|c|}
\hline \multirow{2}{*}{ Quality indicator } & $\begin{array}{c}\text { Limit value } \\
\text { requirements }\end{array}$ & \multicolumn{4}{|c|}{ Value of quality indicator } \\
\cline { 3 - 6 } & Beeline & Megafon & MTS & Tele2 \\
\hline $\begin{array}{l}\text { Voice service non- } \\
\text { accessibility, \% }\end{array}$ & no more than 5 & 0.3 & 0.4 & 0.4 & 0.3 \\
\hline $\begin{array}{l}\text { Voice service cut- } \\
\text { off ratio, \% }\end{array}$ & no more than 5 & 0.4 & 0.7 & 1.7 & 0.1 \\
\hline $\begin{array}{l}\text { Speech quality on } \\
\text { call basis (MOS } \\
\text { POLQA) }\end{array}$ & $\begin{array}{c}\text { not less than } \\
2.6\end{array}$ & 4.1 & 4.1 & 4.0 & 3.9 \\
\hline $\begin{array}{l}\text { Negative MOS } \\
\text { samples ratio, MOS } \\
\text { POLQA < 2.6, \% }\end{array}$ & - & 0.5 & 1.4 & 1.2 & 0.5 \\
\hline
\end{tabular}

TABLE V. THE INDICATORS OF SMS TRANSMISSION QUALITY

\begin{tabular}{|l|c|c|c|c|}
\hline \multirow{2}{*}{ Quality indicator } & \multicolumn{4}{c|}{ Value of quality indicator } \\
\cline { 2 - 5 } & Beeline & Megafon & MTS & Tele2 \\
\hline Undelivered SMS messages, \% & 0.1 & 0.1 & 0.6 & 0.0 \\
\hline $\begin{array}{l}\text { Average SMS messages delivery } \\
\text { time, s }\end{array}$ & 3.0 & 3.6 & 3.5 & 3.5 \\
\hline
\end{tabular}

TABLE VI. THE INDICATORS OF DATA TRANSMISSION QUALITY (EXCLUDING VOICE OVER DATA TRANSMISSION)

\begin{tabular}{|l|c|c|c|c|c|}
\hline \multirow{2}{*}{ Quality indicator } & \multirow{2}{*}{$\begin{array}{c}\text { Limit value } \\
\text { requirements }\end{array}$} & \multicolumn{4}{|c|}{ Value of quality indicator } \\
\cline { 3 - 6 } & Beeline & Megafon & MTS & Tele2 \\
\hline $\begin{array}{l}\text { HTTP IP-Service } \\
\text { Access Failure } \\
\text { Ratio, \% }\end{array}$ & no more than 6 & 0.7 & 1.4 & 0.7 & 0.3 \\
\hline $\begin{array}{l}\text { HTTP Session } \\
\text { Failure Ratio, \% }\end{array}$ & - & 0.8 & 1.5 & 0.8 & 0.3 \\
\hline $\begin{array}{l}\text { HTTP DL Mean } \\
\text { User Data Rate, } \\
\text { kb/s }\end{array}$ & $\begin{array}{c}\text { not less than } \\
80\end{array}$ & 5372.8 & 10347.4 & 10000.9 & 7982.3 \\
\hline $\begin{array}{l}\text { HTTP Session } \\
\text { Time, ms }\end{array}$ & - & 11.66 & 9.54 & 8.54 & 10.85 \\
\hline
\end{tabular}

TABLE VII. REFERENCE DATA

\begin{tabular}{|l|c|c|c|c|}
\hline \multicolumn{1}{|c|}{ Parameter } & \multicolumn{4}{c|}{ Total amount } \\
\cline { 2 - 5 } & Beeline & Megafon & MTS & Tele2 \\
\hline Voice connections & 7878 & 7870 & 7834 & 7859 \\
\hline MOS samples (POLQA) & 148451 & 138380 & 145811 & 148454 \\
\hline $\begin{array}{l}\text { Negative MOS samples (MOS } \\
\text { POLQA<2.6) }\end{array}$ & 738 & 1875 & 1800 & 756 \\
\hline Sent SMS-messages & 1474 & 1490 & 1443 & 1424 \\
\hline $\begin{array}{l}\text { Attempts to connect to HTTP- } \\
\text { server (file loading) }\end{array}$ & 1592 & 2568 & 2247 & 1828 \\
\hline $\begin{array}{l}\text { HTTP sessions (Web- } \\
\text { browsing) }\end{array}$ & 3129 & 4978 & 4347 & 3636 \\
\hline
\end{tabular}

\section{CONCLUSIONS}

1. At present, $100 \%$ of the territory of Tomsk is covered by the 2G cellular networks (GSM 900/1800) of the major carriers. The coverage categories "good" and "normal" occupy summarily: $99.99 \%$ for Beeline, $100 \%$ for Megafon, $99.99 \%$ for MTS, $99.94 \%$ for Tele2. For the analyzed networks, the average level of the received signal is stable and almost of the same value for all the operators.

2. Almost the entire territory of Tomsk is covered by the 3G cellular networks (UMTS) of the four major mobile operators. The continuous coverage on the explored territory occupies: $99.82 \%$ for Beeline, $99.94 \%$ for Megafon, $99.89 \%$ for MTS, 99.94 for Tele2. For the analyzed networks, the level of the received signal differs significantly over Tomsk districts and varies from operator to operator. There are some areas where the signal from base stations is too weak to connect to the network ( $\%$ of the explored territory): $6.84 \%$ for Beeline, $6.3 \%$ for Megafon, $5.58 \%$ for MTS, $4.94 \%$ for Tele2. These areas were localized and plotted on the map of Tomsk, which is available on the Internet [7].

3. Almost the entire territory of Tomsk is covered by $4 \mathrm{G}$ LTE networks: $99.65 \%$ of the explored territory covered by the MegaFon LTE network and $98.01 \%$ by the MTS LTE network. The coverage categories "sufficient" and "low" occupy summarily $88.61 \%$ and $85.5 \%$ of the explored territory, for MegaFon and MTS respectively. Shares of the categories "excellent", "good" and "normal" are negligible for both operators: $1.54 \%$ and $0.01 \%$ of the explored territory for MegaFon and MTS respectively. The results of the measurements show that the coverage quality of 4G LTE networks in Tomsk is far from perfect. There is a need to increase the number of LTE base stations in order to improve 
the coverage quality and provide Tomsk residents with fast mobile Internet access.

4. For all the operators the average speech intelligibility is higher than the minimum required value (2.6). The value of this indicator is practically constant for all the operators. The speech quality is predicted as "good" by the POLQA model. The values of the indicators "voice service non-accessibility" and "voice service cut-off ratio" do not exceed the limited values for all the operators.

5. The value of the indicator "undelivered SMS messages" is highest for MTS $(0.6 \%)$ and the lowest for Tele2 $(0.0 \%)$. Average SMS messages delivery time is approximately of the same value for all the operators.

6. The value of the indicator of data transmission quality "HTTP DL Mean User Data Rate" for operators Megafon and MTS is significantly higher (1.5-2 times) than it is for Beeline and Tele2, which can be explained by the availability of the Megafon and MTS 4G networks (LTE).

7. The availability of $4 \mathrm{G}$ networks can probably explain the relatively high values of the indicators "HTTP IP-Service Access Failure Ratio" and "HTTP Session Failure Ratio" for Megafon and MTS, because the coverage quality of LTE networks remains bad [7].

8. The coverage maps obtained during this study can be used by Tomsk residents to make an informed choice of mobile operator.

9. The techniques described in this paper can be useful for conducting similar research in other cities and countries. It should be noted that the frequency bands used in the same standards may vary from country to country and the set of communication standards may also be different. However, the requirements for carrying out measurements described in the paper, as well as a set of quality indicators, can be extended to them.

\section{SUMMARY}

Publication of the results obtained by disinterested party seems to be extremely useful: it raises the consumers' awareness about the quality of mobile services, encourages the fair competition between mobile operators and ultimately can be an important factor in development of communication infrastructure.

Today we have a big "digital gap" between different regions of Tomsk Oblast. The problem of digital divide is particularly acute in rural areas and villages. To address these issues we are planning to conduct further studies of the quality of mobile communication services in Tomsk Oblast in 2017.

\section{REFERENCES}

[1] Statistika otrasli [The branch statistics]. Available at: http://minsvyaz.ru/ru/activity/statistic/statistika-otrasli (accessed 27.07.2017).

[2] Koncepciya upravleniya kachestvom svyazi v Rossijskoj Federacii (proekt) [The conception of the quality of service management]. Available at: http://minsvyaz.ru/ru/documents/4668 (accessed 27.07.2017).

[3] Rezul'taty drajv-testov v setyah GSM/UMTS za 3 kvartal 2016 goda [The results of drive-tests in GSM/UMTS networks by the 3rd quarter of 2016]. Available at: http://belgie.by/ru/reports (accessed 27.07.2017).

[4] Measuring mobile broadband performance in the UK, $4 \mathrm{G}$ and $3 \mathrm{G}$ network performance. Available at: https://www.ofcom.org.uk/_data/assets/pdf_file/0014/32054/mbbnov14.pdf?lang=en (accessed 27.07.2017).

[5] LTE drive tests in one of Germany's first research mobile radio networks. Available at: https://cdn.rohdeschwarz.com/pws/dl downloads/dl common library/dl news from rs/ 200/N200_TSMW_e.pdf (accessed 27.07.2017).

[6] Metodika ocenki kachestva uslug podvizhnoj radiotelefonnoj svyazi [The methodology for the quality of service assessment in telecommunication networks]. Available at: http://minsvyaz.ru/ru/documents/4473 (accessed 27.07.2017).

[7] Kachestvo svyazi $v$ Tomske [The quality of service in telecommunication networks in Tomsk]. Available at: http://xn-80aeakmgi9azaci1 dvg.xn--p1 ai/sfo/tomsk.html (accessed 27.07.2017).

[8] Shmakov D.B. Analiz kachestva pokrytiya setej svyazi standarta LTE v Tomske [The analysis of coverage quality in LTE networks in Tomsk]. Prirodnye i intellektual'nye resursy Sibiri - Natural and intellectual resources of Siberia, 2016, pp. 139-142.

[9] Shmakov D.B. Kompleksnaya ocenka kachestva uslug sotovoj svyazi v Tomske [The integrated assessment of quality of service in telecommunication networks in Tomsk]. Electronic means and control systems, 2016, part 1, pp. 40-42.

[10] Kannan Srinivasan, Philip Levis. RSSI is Under Appreciated. Available at: https://sing.stanford.edu/pubs/rssi-emnets06.pdf (accessed 27.07.2017). 